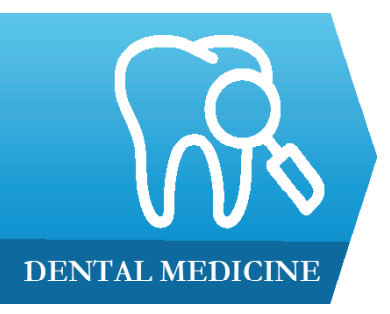

Department of Orthodontics, Narayana Dental College, Nellore, Andhra Pradesh, India

DOI: $10.15386 / \mathrm{mpr}-1843$

Manuscript received: 06.08.2020

Received in revised form: 05.11.2020

Accepted: 09.12.2020

Address for correspondence:

mandavabruno9@gmail.com

This work is licensed under a Creative Commons Attribution-NonCommercialNoDerivatives 4.0 International License

\section{Impact of self-esteem on the relationship between orthodontic treatment and the oral health-related quality of life in patients after orthodontic treatment - a systematic review}

Prasad Mandava, Gowri Sankar Singaraju, Sobitha Obili, Venkatesh Nettam, Sasipriya Vatturu, Seshu Erugu

\begin{abstract}
Objective. The treatment protocol in the modern health care paradigm has shifted considerably towards enhancing the quality of life in the last decade. This is particularly important in cosmetic and elective treatments, and hence the interest in oral healthrelated quality of life (OHRQoL) also has increased. OHRQoL always been measured by endogenous, functional, social, or psychological determinants. Self-esteem (SE) is one of the internal factors that affect the perception of malocclusion and hence OHRQoL before and after treatment. The purpose of this review is to assess whether there exists any correlation between the Oral Health-Related Quality of Life, Selfesteem (SE) in patients following orthodontic treatment.

Methods. A literature search was confined to the English language using Medical Subject Heading terms (MeSH) in PubMed, Cochrane Library, and Ovid $\mathbb{R}$ covering the period from January 1, 1951 to May 15, 2020. Search in Google Scholar, grey literature, and hand search on cross-references was performed to find additional data. The studies found to be suitable were selected based on the predefined inclusion and exclusion criteria. The quality of assessment and risk of bias for the included studies were evaluated independently by two invigilators utilizing "The Cochrane Collaboration's tool for assessing the risk of bias" and "Modified version of the Newcastle Ottawa scale" for Randomized Controlled Trials (RCTs) and nonrandomized trials respectively.
\end{abstract}

Results. A total of 7688 studies were retrieved from all the sources. After screening all the titles and excluding the duplicates, 28 studies were finally included for text review, and all of them were fit for quality appraisal. The design of the final studies included comprised of 3 RCTs, 14 cohort studies, 9 cross-sectional studies, and 2 case-control studies.

Conclusion. There is moderate evidence to show that fixed orthodontic treatment improves OHRQoL and SE in children. OHRQoL also increased in adolescents and adults. However, there is a weak correlation between SE and OHRQoL. More evidence-based studies are needed to analyze the relationship.

Keywords: aesthetics. oral health-related quality of life, orthodontic treatment, perception, self-esteem 


\section{Introduction}

The World Health Organization (WHO) in 1948 defined "Health as a state of complete physical, mental and social well-being and not only the absence of disease or infirmity". Quality of life (QoL) was described as "patients' attitudes of their condition in being in the context of culture and value ways in which they exist and concerning their goals, expectations, standards, and concerns" [1]. Quality of life (QoL) can be affected by poor oral health [2] and assessing Oral Health-Related Quality of Life (OHRQoL) helps professionals to clarify the role of oral health status on the overall quality of life [3].

Orthodontic treatment is disparate from most of the distinct medical interventions by that it aims to correct malocclusion from an arbitrary norm [4]. Besides enhancement of dentofacial aesthetics, orthodontic treatment restores occlusal function. It also improves the psychosocial well-being, which, in turn, results in the betterment of oral health-related quality of life in particular and overall health related quality of life in general $[5,6]$.

The assessment of OHRQoL is recommended in orthodontics for plenty of reasons: to study treatment needs and outcomes, efficiency of the therapy and impact during the stated period of treatment, and as part of clinical trials to potentially enhance the quality of care. Furthermore, understanding patients' expectations of therapy can help detail the parameters for informed consent as well as help patients develop coping methods for dealing with treatment sequelae [5].

Consequently, the interventions in the modern healthcare systems should be directed to address the patient's health complaints, taking into consideration the impact of patients' illness on quality of life (QoL) [7]. Most of the modern dental procedures endeavor to improve patient quality of life [8]. Although improvement of quality of life considered to be the primary goal of orthodontic treatment, it was observed that OHRQoL worsened during the initial part of the treatment [9]. However, a considerable improvement was observed later during the course of the treatment [1012]. This is particularly true with adolescents wearing fixed appliances than those using removable or either of the kinds of appliances simultaneously [13].

Global self-esteem (SE) refers to the feeling and appraisal of oneself as a person. In contrast, specific selfconcepts attribute to the beliefs and values in different domains, such as school competence or close friendship [14]. The concept of self-esteem refers to a person's feeling of self-worth [15]. Higher self-esteem is associated with better dental Health practice [16]. Contrary to OHRQoL, self-esteem is assumed to be a relatively stable trait [17]. Self-esteem was described as a multidimensional concept, for which Harter developed a tool to measure feelings of both global and specific self-worth $[18,19]$.

The escalating emphasis on the necessity for evidence-based health services claims that the evaluation of the effectiveness of orthodontic treatment outcome measures is essential to the patient and the clinician [20-23]. Thus, investigating the OHRQoL in orthodontic patients may provide information that will help clinicians and public health planners in enhancing the quality of orthodontic care as suggested by WHO $[20,24]$. Evidence of negative impact of malocclusion on OHRQoL was observed in previous systematic reviews $[25,26]$. The influence of orthodontic treatment on the OHRQoL have also been reviewed in some other studies [27,28]. Few studies have shown that the orthodontic treatment influences the level of self-esteem, with a marked improvement at the end of treatment $[29,30]$ and while others have found no differences in self-esteem after the completion of orthodontic treatment [31]. The specific results of orthodontic treatment in improving selfesteem are not consistent across these studies. Therefore, to evaluate the possible role of orthodontic treatment in influencing self-esteem after treatment still needs clarity. The present review attempts to explore the relation between these two components.

Self-esteem (SE) influences the Oral health-related Quality of life [10,32], although its specific role, as well as its relation to oral health perceptions, lacks in evidence. The study by Jung [33] on Korean adolescent female population indicated a direct relation between the severity of malocclusion and OHRQL and SE scores. Some studies [34-36] found a significant correlation between OHRQoL and SE. However, the authors were not comprehensible regarding the direction of the association. Although a few systematic reviews discussed the impact of orthodontic treatment on OHRQoL of the patient, till now no systematic review interpreted the relation between the patient's selfesteem and orthodontic treatment. And no review evaluated the correlation between patient's oral health-related quality of life and self-esteem (SE). So, the present systematic review aims to traverse the current literature to identify the changes in the OHRQoL as well as in the self-esteem of the patients following orthodontic treatment procedures. Further, this review assesses the correlation of OHRQoL and $\mathrm{SE}$ in the orthodontic patients after treatment.

\section{Methodology \\ Protocol registration}

The protocol for the present study was registered with the PROSPERO international prospective register (PROSPERO 2020: CRD42020191310) for systematic reviews.

\section{Eligibility criteria}

The selection criteria based on the PICO-s format was applied in this review (Table I).

Information sources, search strategy, study selection and data extraction

An extensive database search was performed in

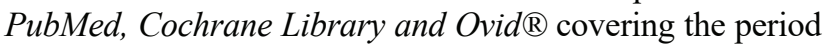
from January 1, 1951 to May 15, 2020. The search was expanded and tapered using Medical Subject Heading terms (MeSH) including the terms "children", "adolescence", 
"adult", "orthodontic treatment", "fixed appliances", "removable appliances", "myofunctional appliances", "oral health-related quality of life", "self-esteem", or by using free text words and their synonyms with multiple combinations using Boolean operators ("or" and "and") and truncations in the English language. A supplementary search was performed in Google scholar and in grey literature. Manual search of the cross-references in the published reviews on the topic were also assessed and studies that met the inclusion criteria were added to the data base. However, the narrative and systemic reviews themselves were not included.

\section{Exclusion criteria}

Studies in which treatment is incomplete, patients assessed for OHRQoL in malocclusion patients without orthodontic treatment or treatment history, surgery patients, cleft palate and cleft lip cases excluded and studies involving adjunctive orthodontic treatment were excluded. Narrative reviews, systematic reviews, conference abstracts and letters to editors were excluded for the present review before the final eligibility.

Two researchers (GS and SR) independently scrutinized the titles of the studies that were retrieved initially from the databases and hand searches. Abstracts of the studies for final review were included after removing the duplicates and irrelevant titles. All the abstracts that satisfied the inclusion criteria were put forth for further full-text review. If there were any unresolved issues regarding the inclusion of a study for the review after fulltext phase, a consensus judgment was taken by employing a third evaluator (PM) who was not involved in the initial screening of the studies. None of the invigilators are blind to the procedure of the study. All the studies which met the criteria were read and evaluated for final eligibility independently by both the researchers.

\section{Data items and collection}

Data extraction was performed independently in a similar method that was utilized for initial evaluation. A piloted electronic excel spreadsheets were utilized to record the data. The following demographic information was recorded: author and year of publication, country, sample size and age, type of study design, type of orthodontic treatment and questionnaire employed.

Method of quality assessment and risk of bias in individual studies

The quality analysis and risk of bias of the included studies was evaluated independently and in duplicate using the same methodology as outlined for selection and data extraction. The "Cochrane risk of bias tool" [37] for randomized controlled trials and "Modified Version of the Newcastle Ottawa scale" [38] for non-randomized trials were utilized respectively. The Cochrane Collaboration tool assess the risk of bias judgment (high, low, or unclear) of included randomized studies for individual elements from five domains (selection, performance, attrition, reporting, and other). After evaluating each key domain, the overall assessment for each study was determined as; "low" if all domains were low; "some concern" if at least one domain was judged to have some concern; and "high" if at least one domain had high or multiple domains were judged to have some concerns in a way that substantially lowered confidence in the result. The modified version of the Newcastle Ottawa scale was designed for case-control studies, cohort studies, and cross-sectional studies. This tool evaluates the studies based on eight domains that were divided into three broad criteria: patient selection, comparability of study groups, and the outcome assessment. A star system for quality assessment was used, whereby high-quality studies at low risk of bias could receive a maximum of 9 stars, studies with 8,7 , or 6 stars are designated as moderate quality, and the studies with low quality were assigned with 5 stars or fewer.

Table I. Selection criteria applied for this review - PICO-S format.

Participants (P): Patients of all age groups undergoing orthodontic treatment. (children, adolescents, adults)

Interventions (I): Any form of orthodontic treatment provided during preventive, interceptive and comprehensive corrective phase of orthodontic treatment. Studies involving treatment either with Fixed or removable orthodontic appliances.

Comparator (C): Studies that included assessment of either of both of OHRQoL and SE during pre- and post-orthodontic treatment. Studies that included a comparison group of subjects who are due for orthodontic treatment and those who have not undergone any form of orthodontic treatment.

\section{Outcome measures $(\mathrm{O})$ :}

1.The main outcome was to measure the OHRQoL and Self-esteem after orthodontic treatment and

2. The secondary outcome was to assess the co-relation between OHRQoL and SE after orthodontic treatment.

The OHRQoL was determined using a validated measures such as the Child Perception Questionnaire (CPQ), Oral impact on daily performance (OIDP), Oral health impact profile (OHIP) and Psychosocial Impact of Dental Aesthetic Questionnaire (PIDAQ).

Self-esteem was measured using the Rosenberg scale, the Dutch adaptation of the Harter's Self-Perception Profile and the Global Negative Self-evaluation.

Study design (S): Randomized clinical and control trials (RCT), prospective cohort studies, and cross-sectional or case-control studies with data collection after orthodontic treatment. 


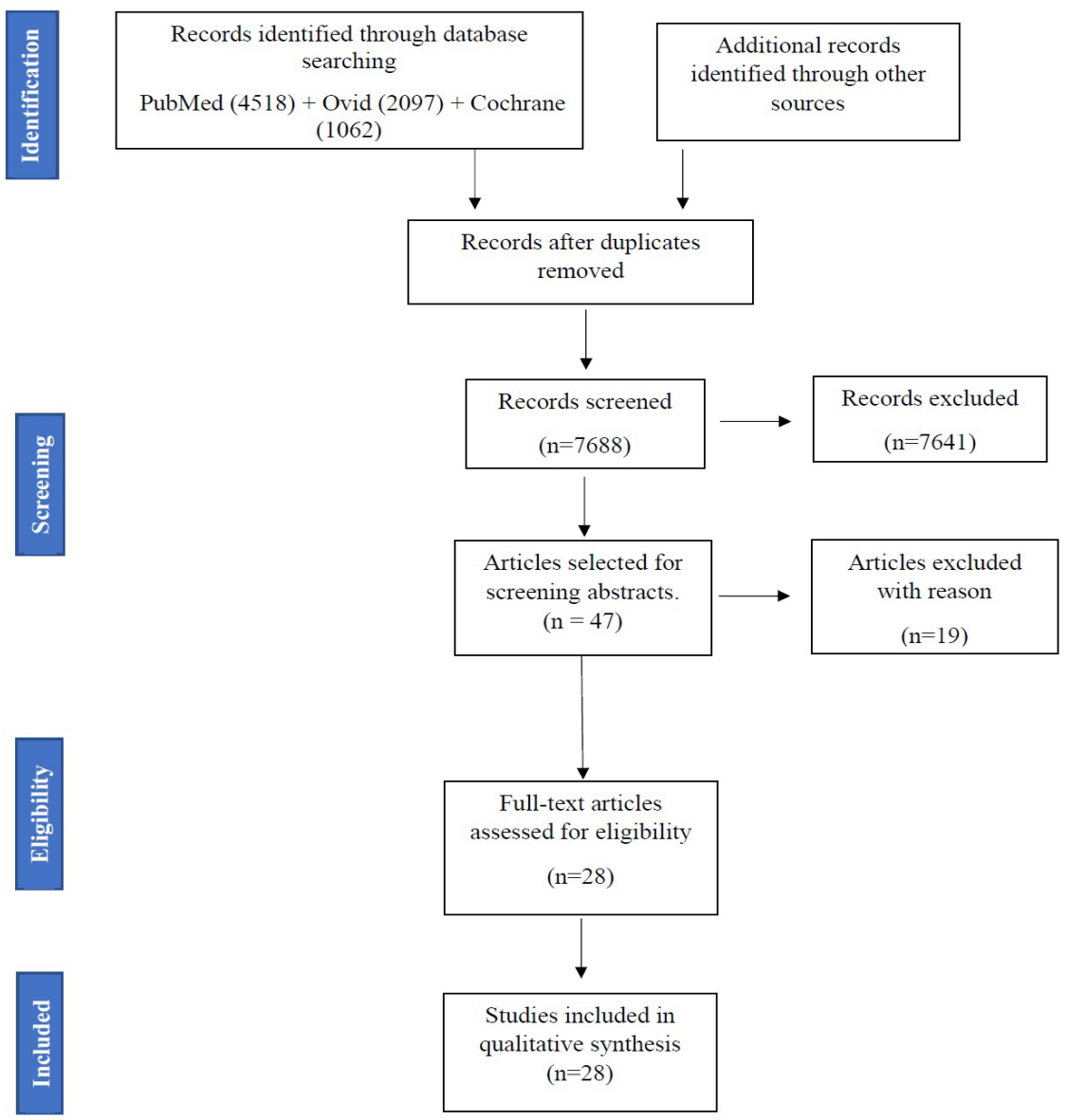

Figure 1. PRISMA flow chart of the included studies.

\section{Results}

A flow diagram explains the retrieval, screening, and selection of articles for the present systematic review (Figure 1). A total of 7688 studies were retrieved after removal of duplicates from all the sources. After screening all the titles, 47 potentially relevant articles were included for the abstract phase from which 19 studies were excluded. Twenty-eight studies were included for text review, and all of them were included for the quality appraisal. The characteristics of the studies such as: author and year of publication, country, number of participants $(\mathrm{N})$, sex, age, the study design ( 3 randomized control trials, 14 cohort studies, 9 cross-sectional studies, and 2 case-controls studies), questionnaire used were depicted (Table II).

Quality assessment and risk of bias in individual studies

The sample sizes in the studies reviewed varied between 28 and 4508 patients. Different studies analyzed different age groups (children, adolescents and adults).
In most of the studies the treatment was done with fixed appliances.

\section{Quality of the studies}

The methodological quality scores, derived from the Newcastle-Ottawa scale, are given in Table III. Overall, 15 studies were considered to have moderate level of quality and 10 studies were judged to be of low quality. None of the studies were assessed to be having high quality since the maximum of 9 stars was not reached even by a single study. Thirteen studies achieved 3 stars and twelve studies scored two or fewer stars for selection of the study groups. Most studies failed to justify their sample sizes; and in less than half of the studies, selection of the control group (or non-respondents for cross-sectional studies) was deemed to be not adequate. Fourteen studies achieved a maximum of 2 stars for the comparability of the study groups. Regarding the ascertainment of the outcome of interest, 2 stars were scored for 21 studies, 1 star scored for 4 studies. 
Table II. Details of the studies analyzed in the Review.

\begin{tabular}{l|l|} 
S.No & $\begin{array}{l}\text { Author and year/ } \\
\text { Country }\end{array}$
\end{tabular}

Participants details

N (losses), \% Sex (n), Mean age (SD), Age range

1 De oliveria [39](2004), Brazil.

$\mathrm{n}=1675(-) ; 56.8 \%$ Female (F) (951), 43.2\% Male (M) (724);15-16 years

pre comprehensive group $(\mathrm{PC})(\mathrm{n}=93) \mathrm{F}-45, \mathrm{M}-48$; Mean age $=12.5(61.1)$ Post interceptive group $(\mathrm{PI})(\mathrm{n}=44), \mathrm{F}-21, \mathrm{M}-23$; Mean age $=12.5$ years (61.1); comparison group $(\mathrm{C})(\mathrm{n}=156)$ F-76, M-80; Mean age $=12$ years 9 months (61.1). Chen [41] (2010), China. $\mathrm{n}=28$ (-), 66.6\% F (148), 33.3\% M (74), 15.7 years.

Agou [35] (2011), Canada.

$\mathrm{n}=199(81), 50 \% \mathrm{M}(59), 50 \% \mathrm{~F}(59), 12.9( \pm 0.98)$ years at $\mathrm{T} 1,11-14$ years.

\section{4}

5

6

7

$8 \quad$ Jang-Mi Kang [43] (2014), Brazil.

9

Yu Zhou [44] (2014), China.

Nathalia B. Palomares [42] 2012, Brazil.

Feu [21] (2013), Brazil.

$$
\text { Treatment (ttm) group- }
$$

$\mathrm{n}=87$ (5), $\mathrm{M}-47, \mathrm{~F}-45$, Mean age- $12-15$ years:

Waiting group- $\mathrm{n}=101$ (23), M -60, F-64; Mean age -12-15 years:

School Group- $\mathrm{n}=96(6), \mathrm{M}-42, \mathrm{~F}-60$; Mean age $-12-15$ years:

$\mathrm{n}=860(-), \mathrm{M}-378, \mathrm{~F}-482$; Mean age- $25.92 \pm 5.30$ years.

$\mathrm{n}=150(-), \mathrm{M}-58, \mathrm{~F}-92$; Mean age of $15.6 \pm 1.8$ years. Divided in to two groups, self-ligating $(\mathrm{n}=75)$ and conventional bracket. $(\mathrm{n}=75)$

Angle class I group

Zheng [46]

11 (2015), ShanDong, China.

Angle class II group

$\mathrm{n}=32$ (5); M -15, F -17; Div- 15-20 years- $\mathrm{n}=19,20-25$ years- $\mathrm{n}=13$ :

Angle class III group

$\mathrm{n}=14$ (0);M -8, F -6;Div- 15-20 years- $\mathrm{n}=9,20-25$ years- $\mathrm{n}=5$ :

Abdolreza Jamilian [47] (2016), Iran.$$
\mathrm{n}=100
$$

Kolenda [48] (2016), Germany. Zealand.$$
\mathrm{St}=
$$

Start of treatment:

$\mathrm{n}=174(0) ; \mathrm{M}-62, \mathrm{~F}-112$; Mean age-13.4 $( \pm 1.3)$ years.

End of treatment: $\mathrm{n}=104(0) ; \mathrm{M}-32, \mathrm{~F}-72$; Mean age-13.5 $( \pm 1.3)$

Fixed appliance

$15 \quad$ Emad EM Alzoubi [49] (2017), Malta.

Miamoto [50] (2018), Brazil. $\mathrm{n}=98(-)$; M-20, F -29; Mean age -16 years

Functional appliance

Total $\mathrm{n}=30(-)$ :

Group I- $\mathrm{n}=15 ; \mathrm{M}-11, \mathrm{~F}-4$; mean age was $9.07 \pm 0.79$ years.

Group II- $\mathrm{n}=15$; M -7, F -8; mean age was $9.00 \pm 0.84$ years. $\mathrm{n}=98(-)$; M-20, F -29; Mean age -10 years
1. Study design

2. Type of orthodontic

treatment

3. Questionnaire/Instrument

1. CSS,

2. FOA

3. OIDP and OHIP-14

1. CSS

2. FOA

3. CPQ11-14

1. Cohort,

2. FOA,

3.OHIP-14

1. C-C,

2. FOA,

3. CPQ 11-14

1. CSS

2. FOA

3. OHIP-14

1. CSS

2. FOA

3. OHIP

1. Cohort

2. FOA

3. OHIP-14

1. CSS,

2. FOA,

3.OHIP-14 and PIDAQ

1. Cohort,

2. FOA,

3. OHIP-14

1. Cohort,

2. FOA,

3.OHIP-14

1. Cohort

2. FOA

3. OHIP-14

1. Cohort,

2. FOA,

3. OHIP-14

1. Cohort

2. FOA

3. OHIP-G14

1. Cohort

2. FOA

3. CPQ 11-14

1. RCT

2. FOA/ROA (functional)

3. OHIP-16

1. RCT

2. ROA

3. $\mathrm{CPQ} 8-10$ 
Table II. Details of the studies analyzed in the Review (continuation).

\begin{tabular}{l|l|l|} 
S.No & $\begin{array}{l}\text { Author and year/ } \\
\text { Country }\end{array}$ \\
\cline { 3 - 3 } & & Na
\end{tabular}

\begin{tabular}{l} 
Participants details \\
\hline N (losses), \% Sex (n), Mean age (SD), Age range
\end{tabular}

Pithon [51](2019),
Bahia, Brazil.

Pithon [51] $(2014$
Bahia, Brazil.

Demirovic [52] (2019), Herzegovina. $\mathrm{n}=80(-), \mathrm{M}-19, \mathrm{~F}-21 ;$ Age range $8-10$ years/

$\mathrm{n}=178(-)$; Mean age -range 22.71 years; experimental group $\mathrm{n}=90$, control group $\mathrm{n}=88$ untreated subjects.
1. Study design/

2. Type of orthodontic

treatment

3. Questionnaire/Instrument

1. RCT

2. FOA

3. CPQ8-10

1. C-C

2. FOA

3. OHIP-14

\section{OHRQoL and SE}

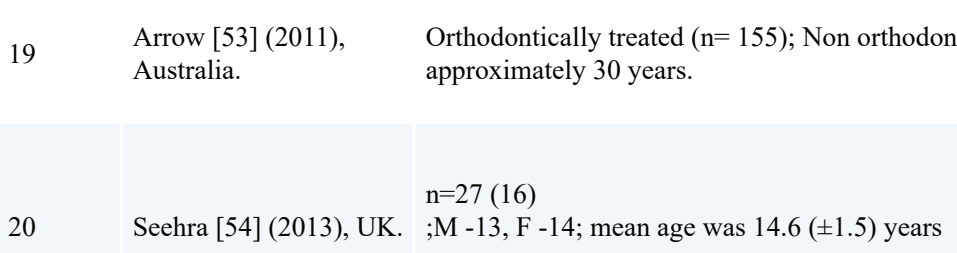

$\begin{array}{lll}21 & \text { Brosens [55](2013), } & \mathrm{n}=27(16) \\ \text { Belgium. } & \mathrm{M}-50, \mathrm{~F}-59 ; \text { Age range- } 11-16 \text { years. }\end{array}$

22 Johal [56] (2015), UK $n=61$ (1), the mean age of 41.2 years

$23 \begin{array}{ll}\text { Benson [36]. (2015), } & \mathrm{n}=374 \text { (30), M-122, F -252; Age 11-12 years. } \\ \text { UK. } & \text { Group II } \\ & n=217 \text { (41), M-61, F-156; Age 14-15 years. }\end{array}$

24 Choi [57] (2017), Korea. n=66(-), M-20, F-36; Mean age $-24.2 \pm 5.2$ years.

Jaeken [58]. (2019), $\quad$ n=497(173), M-239,F-259; Mean age - 12.7 years.
Belgium.

\section{Cohort}

2. FOA

3. OHIP-14 and Rosenberg

Scale

1. Cohort

2. FOA,

functional and retainers

3. CPQ 11-14

and Harter's Self Perception Profile

1. Cohort

2. FOA

3. CPQ and Harter's Self-

Perception Profile.

1. Cohort

2. FOA

3. Rosenberg Self-esteem scale, OHIP-14

1. Cohort

2. FOA

3. CPQ11-14 and CHQ-CF87

1. CSS

2. FOA

3. Rosenberg self-esteem scale and OHIP-14

1. Cohort

2. FOA

3. CPQ11-14, Harter's SelfPerception Profile.

\section{SE}

\begin{tabular}{|c|c|c|}
\hline 26 & $\begin{array}{l}\text { Jung [29]. (2010), } \\
\text { Korea. }\end{array}$ & $\begin{array}{l}\text { Total } n=4509(-) \\
\text { M-1565, F-2944; Middle school aged, } 10-13 \text { years. }\end{array}$ \\
\hline 27 & $\begin{array}{l}\text { Romero [59]. (2015), } \\
\text { Spain. }\end{array}$ & $\mathrm{n}=170(-)$, M-70, F-100; Mean age $-29.80-+9.55$ years \\
\hline 28 & $\begin{array}{l}\text { Avontroodt [60] (2019), } \\
\text { Belgium. }\end{array}$ & $\mathrm{n}=326(-), \mathrm{M}-154, \mathrm{~F}-172 ;$ Mean age $-13.1 \pm 1.18$ years at $\mathrm{T} 0$ \\
\hline
\end{tabular}
1. Cohort
2. FOA
3. Rosenberg's scale
1. CSS
2. FOA
3. Rosenberg's scale.
1. Cohort
2. FOA
3. Dutch adaptation of the Harter's test and treatment Need.

Participant characterstics - Male (M), Female (F); Instrument/Questionnaire- Child Perception Questionnaire (CPQ), Oral health impact profile (OHIP) Oral impact on daily performance (OIDP), Psychosocial Impact of Dental Aesthetic Questionnaire (PIDAQ); Type of study- Cross sectional study (CSS), prospective cohort studies (Cohort), case control study (C-C), Randomized control trial (RCT); Type of Appliance - Fixed orthodontic appliance (FOA), Removable Appliance (ROA), Debonding (DB). 
Table III. Quality assessment for non-randomized studies: Modified Newcastle Ottawa scale.

\begin{tabular}{|c|c|c|c|c|c|c|c|c|c|c|c|}
\hline \multirow{2}{*}{\multicolumn{2}{|c|}{\begin{tabular}{l|l} 
S. no & Author (year) \\
OHRQL
\end{tabular}}} & \multicolumn{4}{|c|}{$\begin{array}{c}\text { Selection } \\
(* * * *)\end{array}$} & \multicolumn{2}{|c|}{$\begin{array}{c}\text { Comparability } \\
(* *)\end{array}$} & \multicolumn{3}{|c|}{$\begin{array}{c}\text { Outcome } \\
(* * *)\end{array}$} & \multirow[t]{2}{*}{$\begin{array}{l}\text { Total } \\
\text { score }\end{array}$} \\
\hline & & 1 & 2 & 3 & 4 & $5 a$ & $5 b$ & 1 & 2 & 3 & \\
\hline 1 & De oliveria [39] (2004) & $*$ & * & $*$ & & $*$ & $*$ & & $*$ & * & 7 \\
\hline 2 & Taylor et al [40] (2009) & $*$ & $*$ & $*$ & & $*$ & $*$ & & $*$ & * & 7 \\
\hline 3 & Chen [41] (2010) & & $*$ & $*$ & & * & & & $*$ & * & 6 \\
\hline 4 & Agou [35] (2011) & $*$ & $*$ & $*$ & & $*$ & $*$ & & $*$ & * & 7 \\
\hline 5 & Navabi [20] (2012) & $*$ & $*$ & $*$ & & $*$ & $*$ & & * & * & 7 \\
\hline 6 & Palomares [42] (2012) & $*$ & $*$ & $*$ & & $*$ & $*$ & & $*$ & $*$ & 7 \\
\hline 7 & Feu [21] (2013) & $*$ & $*$ & $*$ & & * & $*$ & & $*$ & * & 7 \\
\hline 8 & Jang-Mi Kang [43] (2014) & & $*$ & $*$ & & $*$ & $*$ & & $*$ & * & 6 \\
\hline 9 & Yu Zhou [44] (2014) & & & $*$ & & & $*$ & & $*$ & * & 4 \\
\hline 10 & Chen [45] (2015) & $*$ & $*$ & $*$ & & $*$ & $*$ & & $*$ & * & 7 \\
\hline 11 & Zheng [46] (2015) & $*$ & $*$ & $*$ & & $*$ & $*$ & & $*$ & * & 7 \\
\hline 12 & Abdolreza Jamilian [47] (2016) & $*$ & $*$ & $*$ & & * & $*$ & & * & $*$ & 7 \\
\hline 13 & Jana Kolenda [48] (2016) & & & $*$ & & & $*$ & & $*$ & * & 4 \\
\hline 14 & Healey [6] (2016) & $*$ & & $*$ & & & $*$ & & $*$ & * & 5 \\
\hline 15 & Demirovic [52] (2019) & $*$ & $*$ & $*$ & & * & $*$ & & $*$ & $*$ & 7 \\
\hline \multicolumn{12}{|c|}{ SE \&OHRQL } \\
\hline 16 & Arrow [53] (2011) & $*$ & $*$ & $*$ & & $*$ & $*$ & & $*$ & $*$ & 7 \\
\hline 17 & Seehra [54] (2013) & & $*$ & $*$ & & & $*$ & & $*$ & * & 5 \\
\hline 18 & Brosens [55] (2013) & $*$ & & $*$ & & & $*$ & & $*$ & * & 5 \\
\hline 19 & Johal [56] (2015) & $*$ & & $*$ & & & $*$ & & $*$ & * & 5 \\
\hline 20 & Benson [36] (2015) & $*$ & & $*$ & & & $*$ & & $*$ & & 4 \\
\hline 21 & Choi [57] et al. (2017) & $*$ & & $*$ & & & $*$ & & $*$ & * & 5 \\
\hline 22 & Jaeken [58] et al. (2019) & $*$ & & $*$ & & & $*$ & & $*$ & & 4 \\
\hline \multicolumn{12}{|l|}{ SE } \\
\hline 23 & Jung [29] (2010) & $*$ & $*$ & $*$ & & $*$ & $*$ & & & * & 6 \\
\hline 24 & Romero [59] (2015) & $*$ & $*$ & $*$ & & $*$ & $*$ & & $*$ & $*$ & 7 \\
\hline 25 & Avontroodt [60] (2019) & $*$ & & $*$ & & & $*$ & & $*$ & & 4 \\
\hline
\end{tabular}

High-quality at low risk of bias could get a maximum of 9 stars, articles achieving 8, 7, or 6 stars have moderate quality, and articles with 5 stars or fewer signified low quality.

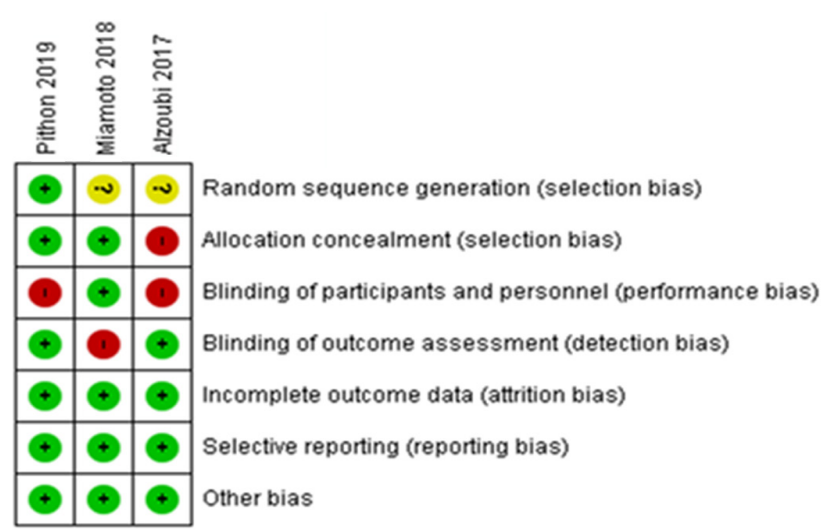

Figure 2. Risk of bias summary: review authors' judgments about each risk of bias item for each included study.

The methodologic quality scores, derived from the Cochrane risk of bias tool for RCTs are shown in (Figure 2 and Figure 3). It can be inferred that two of the studies can be rated of low quality. Trials conducted by Alzoubi [49] and Miamoto [50] had high selection bias and detection bias. Random sequence generation was unclear in these two studies and the study of Pithon [51] reflected an acceptable quality (only performance bias was high).

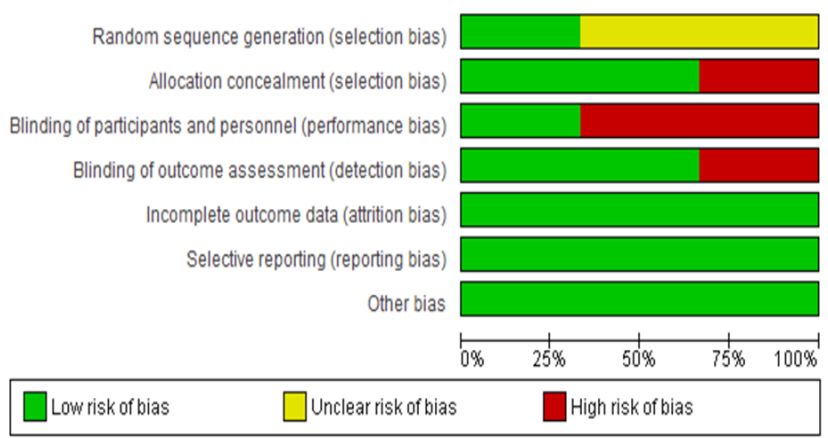

Figure 3. Risk of bias graph: review authors' judgments about each risk of bias item presented as percentages across all included studies. 


\section{Measuring tools used}

The instrument used for outcome measurement of OHRQoL was the Child Perception Questionnaire 11-14 in 9 studies $[6,36,40,35,50,51,55,56,59]$ and the remaining 16 studies [21,22,39,41-49,52,53,56,57] utilised the Oral Health Impact Profile-14 (OHIP-14) or the Oral Impacts on Daily Performance (OIDP) instrument. The selfesteem outcome measure used in 4 studies $[54,55,58,60]$ was the Harter's Self-Perception Profile, five studies $[29,53,56,57,59]$ used the Rosenberg's self-esteem scale and 1 study used CHQ-CF87) [36].

\section{OHRQoL, SE and OHRQoL+SE relation OHRQoL}

The studies in which OHRQoL assessed were twenty-five, out of which 22 studies showed an increase in OHRQoL, and three studies showed no improvement in OHRQoL after orthodontic treatment).

Self-esteem was evaluated in 10 studies [29,36,5360] (4 studies showed a decrease in SE while equal number of studies showed an increase in SE and one study showed no change in global SE.

SE and OHRQol: The correlation between SE and OHRQol was analyzed in 7 studies [36,53-58] (4 studies showed negative correlation, two studies showed a positive correlation, and 1 study showed an increase in OHRQol but no change in SE, inferring that no relation exists between OHRQoL and SE. Negative correlation implies that as the OHRQoL increased, there was a decrease in SE by the end of treatment. Whereas, positive correlation concludes that both OHRQoL and SE increased after appliance therapy.

\section{Age factor}

Children: Of the 28 studies evaluated, 8 studies $[22,36,35,49-51,55,58]$ included child population (only OHRQoL analysed in 5 studies, both SE and OHRQoL examined in 3 studies, so totally 8 studies analysed OHRQoL). In all of these studies, children exhibited an increase in OHRQoL and SE in all the studies after orthodontic treatment.

Adolescence: In this age group, 11 studies $[6,29,39-41,44,46,47,52,54,60]$ were analysed. The only OHRQoL was examined in 8 studies, only SE in 2 studies, both SE and OHRQoL in 1 study; so totally OHRQoL was examined in $9(8+1)$ studies, SE in $3(2+1)$ studies, both SE and OHRQoL in 1 study. In adolescents, there was an improvement in OHRQoL in seven of the studies $[39,41,44,46,47,52,54]$ and 2 studies [6,40] showed no change in OHRQoL after therapy. Regarding the SE in adolescents, One study [29] displayed improvement in SE, where as another study [60] showed no improvement in overall global SE. However, females showed a decrease in SE, and males showed an increase in SE.

Adults: The adult population was analyzed in eight studies [21,42,43,48,53,56,57,59] (only OHRQoL in 4 studies, only SE in 1 studies, both SE and OHRQoL in 3 studies; so totally OHRQoL in $7(4+3)$ studies, SE in $4(1+3)$ studies, both SE and OHRQoL in $3(1+2)$ studies and a single study [45] included young adult where only OHRQoL was analyzed. In adults, six studies $[21,42,43,48,56,57]$ displayed an increase while as one study [53] exhibited negative trends in the OHRQoL after orthodontic treatment. In all the adults, SE increased after treatment. In young adults, an increase in OHRQoL [45] after orthodontic treatment was observed.

\section{Gender factor}

One study on young adolescents, middle school aged (10-13 years) came across an increase in SE in males compared to females [29] while as another study reported entirely the opposite trend [60].

\section{Fixed vs. Removable appliances}

Of the 28 studies included in the study, 26 studies used fixed appliances, whereas two studies used removable devices (1 research: myofunctional and another study: removable appliance with digital springs). The two studies in which were used removable appliances $[49,50]$ were of low quality in quality assessment, whereas in a total of 23 studies analyzed for OHRQoL, fixed appliances showed increase in quality of life in 20 studies $[21,22,35,36,39,41,42-34,51,54-58]$ and no improvement of QoL in 3 studies $[6,40,53]$. Three of the studies $[29,59,60]$ assessed self-esteem in which only fixed appliances were used; no study was present to analyze the SE with removable appliances. The results extracted from the studies included are summarised (Table II).

\section{Discussion}

OHRQoL and SE assessment are the essential components of any treatment, and accomplishment of the same is necessary for any preventative or therapeutic treatment. The evaluation should be done while treating a malocclusion because of the significant psychosocial aspects involved in treating malocclusion. The patientreported outcome measure (PROM) is "any declaration of the status of a patient's health condition that comes straight from the patient, without interpretation of the patient's response by a doctor or anyone else". In the future, PROMs will be the standard of outcome assessment compared to clinical and peer review or caregiver assessment. Patientreported experience measures were also used as quality indicators of patient care and safety [61].

The current systematic review was set out to summarize the evidence for changes in the OHRQoL, SE of children, adolescent and adults in treatment with fixed and removable appliances and the correlation between SE and OHRQoL in patients at the end of orthodontic treatment. This systematic review focused on the results of OHRQoL, SE separately and both in combination 
after treatment in all age groups. The review attempted to identify the relation between SE and OHRQoL after orthodontic treatment. This which makes the present review unique as compared to the previous studies in this context.

From the review of the studies, it can be concluded that orthodontic treatment utilizing fixed appliances produces a significant improvement in both the selfesteem and oral health-related Quality of life in children. However, there is ambiguity in the evidence whether there is an increase or decrease in SE in the adolescents and the adult patients by the end of the treatment. A positive association was found between OHRQL and SE in orthodontic treatment in children. Individually selfesteem and oral health-related quality values increased post orthodontic treatment (fixed and removable appliances). Utilizing removable appliance [49,50] showed significant improvement in OHRQoL in children by the end of treatment, and no study for self-esteem has used removable appliances.

There are diagonally contradictory reports from two studies available based on gender assessment $[29,60]$. Both these studies were done in young adolescents between 10-16 years. A study by Jung [29] on Korean mid school going adolescents unveiled that after fixed orthodontic treatment, the girls had higher self-esteem than the untreated malocclusion group compared to boys. Further the study revealed that the malocclusion had significant effects on the self-esteem of females where as in boys it has no effect. Whereas, the study by Avontroodt [60] in Belgium revealed a decrease of SE in females, whereas in males SE increased after orthodontic treatment. This might have been due to differences in the demographic characteristics of the samples under the individual study.

The findings of the present review should be viewed in the clinical context. The self-perception of the dentofacial esthetics influence psychological development from early childhood to adulthood. The self-perception can boost the self-concept and hence the self-esteem. In recent decades, QOL has been used to evaluate patient perspective in the form of subjective awareness, with a particular focus on patient-reported outcome measures (PROM). In general, self-esteem or one's overall evaluation or appraisal of one's own value is associated with greater life satisfaction. It is reasonable to assume that the relationship between reported OHRQoL and malocclusion and treatment effects is most likely mediated by innate psychological attributes, such as selfesteem SE, in predicting the effect of health conditions on the quality of life. The evidence from the present review supports the mediator role of SE when evaluating OHRQoL in children. So within reasonable limits, it can be recommended that the early treatment of malocclusion should be carried out if possible.

The findings of the current systematic review concur with earlier studies which have concluded that improvements in OHRQoL were associated with orthodontic treatment [20,59]. Concerning the overall results of the studies, Benson and colleagues [36] found a moderate increase in CPQ11-14 scores among patients with orthodontic treatment history. However, the relationship between the history of orthodontic treatment and the QoL improvement was not statistically significant [36]. It is essential to note the systematic review and meta-analysis published by Javidi and co-workers, [28] as qualitative analysis obtained similar results to our study. However, the earlier review suggested no significant differences between patients who underwent orthodontic treatment and those who did not. A systematic review conducted by Ferrando-Magraner and co-workers [62] concluded that there is a positive relationship among oral health-related quality of life and orthodontic treatment and in tandem with the present review. Thus, it can be summarized that OHRQoL is improved with fixed mechanotherapy, however sufficient quantity of studies were not available to compare the same with the removable appliances.

There are certain methodological limitations in interpreting the results of this systematic review. The level of the evidence is based on the type of studies. Unfortunately, due to specific methods used in Randomised Clinical Trials, it is not possible to have an interventional and a comparable control group to assign and follow up the subjects for a long time due to ethical concerns. This is reflected in the present review by very little evidence documented in the form of RCTs in response to the research query. This may handicap the level of evidence to the research question. The quality and methodology of the non-randomised control studies incorporated in the present systematic review is questionable and point towards the need for further quality research so as to analyze the correlation between SE and OHRQoL in patients undergoing orthodontic treatment, particularly with the removable appliance. Second one is the outcome measurements OHRQoL and SE were pooled and analyzed. Different questionnaires were used in these studies to evaluate OHRQoL and SE. The individual questionnaires may mediate different domains of importance. The individual domains are not analysed in the present study. Besides there are certain inherent limitations when analysing the systematic reviews on the orthodontic treatment. The Orthodontic treatment is unique because of varied manifestations of malocclusions. The data cannot be analysed based on the individual type of malocclusions. Further studies should be conducted with clearly defined age ranges, balanced distribution of gender, longitudinal follow-up, with reduced loss of follow-up, and using uniform validated and reliable assessment instrument and should be analyzed after treatment but not during the individual phases of the treatment procedure. 


\section{Conclusions}

From the analysis of the present systematic review, it is reasonable to conclude that there is moderate evidence showing that fixed orthodontic treatment improves OHRQoL in all the age groups. There is definite increase in the SE in children, but not positively consequential in adults and adolescents. The age and gender affect the domain of self-esteem in young adolescents, but the direction of the effect based on gender is not clear. From the available data the relation between OHRQoL and SE in inclined slightly towards negativity.

\section{References}

1. World Health Organization. Preamble to the constitution of the World Health Organization as adopted by the International Health Conference. New York, 19-22 June, 1946; signed on 22 July 1946 by the representatives of 61 States (Official Records of the World Health Organization, no. 2, p. 100) and entered into force on 7 April 1948. available at https://apps.who. int/iris/bitstream/handle/10665/44192/9789241650472_eng. pdf;jsessionid=C1FCD71166753209504F48F3B6608742?s equence $=1$

2. Gift HC, Atchison KA. Oral health, health, and health-related quality of life. Med Care. 1995;33(11 Suppl):NS57-NS77.

3. Cunningham SJ, Hunt NP. Quality of life and its importance in orthodontics. J Orthod. 2001;28(2):152-158.

4. O'Brien K, Kay L, Fox D, Mandall N. Assessing oral health outcomes for orthodontics--measuring health status and quality of life. Community Dent Health.1998;15: 22-26.

5. Mortensen MG, Kiyak HA, Omnell L. Patient and parent understanding of informed consent in orthodontics. Am J Orthod Dentofacial Orthop. 2003;124:541-550.

6. Healey DL, Gauld RD, Thomson WM. Treatment-associated changes in malocclusion and oral health-related quality of life: A 4-year cohort study. Am J Orthod Dentofacial Orthop. 2016;150:811-817.

7. Sischo L, Broder HL. Oral health-related quality of life: what, why, how, and future implications. J Dent Res. 2011;90:1264-1270.

8. Schaffhuser K, Allemand M, Schwarz B. The development of self-representations during the transition to early adolescence: The role of gender, puberty, and school transition. J Early Adolesc. 2017;37:774-804.

9. Rosenberg M, Schooler C, Schoenbach C, Rosenberg F. Global self-esteem and specific self-esteem: Different concepts, different outcomes. Am Sociol Rev. 1995;1:14156 .

10. Kragt L, Wolvius EB, Jaddoe VWV, Tiemeier H, Ongkosuwito EM. Influence of self-esteem on perceived orthodontic treatment need and oral health-related quality of life in children: the Generation R Study. Eur J Orthod. 2018;40:254-261.

11. Trzesniewski KH, Donnellan MB, Robins RW. Stability of self-esteem across the life span. J Pers Soc Psychol. $2003 ; 84: 205-220$.
12. Treffers AW, Goedhart AW, Veerman JW, Van den Bergh BR, Ackaert L, De Rycke L. Handleiding competentie belevingsschaal voor adolescenten [Manual of the Perceived Competence Scale for adolescents]. Lisse: Swets \& Zeitlinger. 2002.

13. Harter S. Self-perception profile for adolescents: Manual and questionnaires. Denver, CO: Univeristy of Denver, Department of Psychology. 2012.

14. Petersen PE. The World Oral Health Report 2003: continuous improvement of oral health in the 21st century--the approach of the WHO Global Oral Health Programme. Community Dent Oral Epidemiol. 2003;31 Suppl 1:3-23.

15. Inglehart MR, Bagramian R, editors. Oral health-related Quality of life. Quintessence Pub.; 2002.

16. Macgregor ID, Regis D, Balding J. Self-concept and dental health behaviours in adolescents. J Clin Periodontol. 1997;24:335-339.

17. Sayers MS, Newton JT. Patients' expectations of orthodontic treatment: part 2 - findings encefrom a questionnaire survey. J Orthod. 2007;34:25-35.

18. Proffit WR, Fields Jr HW, Sarver DM. Malformation and Dentofacial Deformity in Contemporary Society. In: Dolan J, editor. Contemporary orthodontics. 4th ed. Philadelphia: Mosby Elsevier. 2014. p. 16-17.

19. Costa AA, Ferreira MC, Serra-Negra JM, Pordeus IA, Paiva SM. Impact of wearing fixed orthodontic appliances on oral health-related quality of life among Brazilian children. J Orthod. 2011;38:275-281.

20. Navabi N, Farnudi H, Rafiei H, Arashlow MT. Orthodontic treatment and the oral health-related quality of life of patients. J Dent (Tehran). 2012;9:247-254.

21. Feu D, Miguel JA, Celeste RK, Oliveira BH. Effect of orthodontic treatment on oral health-related quality of life. Angle Orthod. 2013;83:892-898.

22. Bernabe E, Sheiham A, de Oliveira CM. Impacts on Daily Performances Related to Wearing Orthodontic Appliances: A Study on Brazilian Adolescents. Angle Orthod. 2008;78:482-486.

23. Hujoel PP. Levels of clinical significance. J Evid Based Dent Pract. 2004;4:32-36.

24. Liu Z, McGrath C, Hägg U. The impact of malocclusion/ orthodontic treatment need on the quality of life. A systematic review. Angle Orthod. 2009;79:585-591.

25. Dimberg L, Arnrup K, Bondemark L. The impact of malocclusion on the quality of life among children and adolescents: a systematic review of quantitative studies. Eur J Orthod. 2015;37:238-247.

26. Kragt L, Dhamo B, Wolvius EB, Ongkosuwito EM. The impact of malocclusions on oral health-related quality of life in children-a systematic review and meta-analysis. Clin Oral Investig. 2016;20:1881-1894.

27. Zhou Y, Wang Y, Wang X, Volière G, Hu R. The impact of orthodontic treatment on the quality of life a systematic review. BMC Oral Health. 2014;14:66.

28. Javidi H, Vettore M, Benson PE. Does orthodontic treatment before the age of 18 years improve oral health-related quality 
of life? A systematic review and meta-analysis. Am J Orthod Dentofacial Orthop. 2017;151:644-655.

29. Jung MH. Evaluation of the effects of malocclusion and orthodontic treatment on self-esteem in an adolescent population. Am J Orthod Dentofacial Orthop. 2010;138:160 166.

30. Vaida L, Pirte A, Corega C, Slăvescu D, Muţiu G. Correlations between the changes in patients' dental-facial morphology at the end of the orthodontic treatment and the psychological variables. Rom J Morphol Embryol. 2009;50:625-629.

31. Birkeland K, Bøe OE, Wisth PJ. Relationship between occlusion and satisfaction with dental appearance in orthodontically treated and untreated groups. A longitudinal study. Eur J Orthod. 2000;22:509-518.

32. De Baets E, Lambrechts H, Lemiere J, Diya L, Willems G. Impact of self-esteem on the relationship between orthodontic treatment need and oral health-related quality of life in 11- to 16-year-old children. Eur J Orthod. 2012;34:731-737.

33. Jung MH. An evaluation of self-esteem and quality of life in orthodontic patients: effects of crowding and protrusion. Angle Orthod. 2014;85:812-819.

34. Agou S, Locker D, Streiner DL, Tompson B. Impact of selfesteem on the oral-health-related quality of life of children with malocclusion. Am J Orthod Dentofacial Orthop. 2008;134:484-489.

35. Agou S, Locker D, Muirhead V, Tompson B, Streiner DL. Does psychological well-being influence oral-health-related quality of life reports in children receiving orthodontic treatment? Am J Orthod Dentofacial Orthop. 2011;139:369377.

36. Benson PE, Da'as T, Johal A, Mandall NA, Williams AC, Baker SR, et al. Relationships between dental appearance, self-esteem, socio-economic status, and oral health-related quality of life in UK schoolchildren: A 3-year cohort study. Eur J Orthod. 2015;37:481-490.

37. Higgins JP, Altman DG, Gøtzsche PC, Jüni P, Moher D, Oxman AD, et al. The Cochrane Collaboration's tool for assessing risk of bias in randomized trials. BMJ. 2011;343:d5928.

38. Hartling L, Milne A, Hamm MP, Vandermeer B, Ansari M, Tsertsvadze A, et al. Testing the Newcastle Ottawa Scale showed low reliability between individual reviewers. J Clin Epidemiol. 2013;66:982-993.

39. de Oliveira CM, Sheiham A. Orthodontic treatment and its impact on oral health-related quality of life in Brazilian adolescents. J Orthod. 2004;31:20-27; discussion 15

40. Taylor KR, Kiyak A, Huang GJ, Greenlee GM, Jolley CJ, King GJ. Effects of malocclusion and its treatment on the quality of life of adolescents. Am J Orthod Dentofacial Orthop. 2009;136:382-392.

41. Chen M, Wang DW, Wu LP. Fixed orthodontic appliance therapy and its impact on oral health-related quality of life in Chinese patients. Angle Orthod. 2010;80:49-53.

42. Palomares NB, Celeste RK, Oliveira BH, Miguel JA. How does orthodontic treatment affect young adults' oral healthrelated quality of life? Am J Orthod Dentofacial Orthop. 2012; 141:751-758.
43. Kang JM, Kang KH. Effect of malocclusion or orthodontic treatment on oral health-related quality of life in adults. Korean J Orthod. 2014;44:304-311.

44. Zhou Y, Zheng M, Lin J, Wang Y, Ni ZY. Self-ligating brackets and their impact on oral health-related quality of life in Chinese adolescence patients: a longitudinal prospective study. ScientificWorldJournal. 2014;2014:352031.

45. Chen M, Feng ZC, Liu X, Li ZM, Cai B, Wang DW. Impact of malocclusion on oral health-related quality of life in young adults. Angle Orthod. 2015;85:986-991.

46. Zheng DH, Wang XX, Su YR, Zhao SY, Xu C, Kong C, et al. Assessing changes in quality of life using the Oral Health Impact Profile (OHIP) in patients with different classifications of malocclusion during comprehensive orthodontic treatment. BMC Oral Health. 2015;15:148.

47. Jamilian A, Kiaee B, Sanayei S, Khosravi S, Perillo L. Orthodontic treatment of malocclusion and its impact on oral health-related quality of life. Open Dent J. 2016;10:236-241.

48. Kolenda J, Fischer-Brandies H, Ciesielski R, Koos B. Oral health-related quality of life after orthodontic treatment for anterior tooth alignment: association with emotional state and sociodemographic factors. J Orofac Orthop. 2016;77:138-145.

49. Alzoubi EE, Hariri R, Mulligan K, Attard N. An evaluation of oral health-related quality of life in orthodontic patients treated with fixed and twin blocks appliances. J Orthod Sci. 2017;6:65-70.

50. Miamoto CB, Marques LS, Abreu LG, Paiva SM. Impact of two early treatment protocols for anterior dental crossbite on children's quality of life. Dental Press J Orthod. 2018;23:7178.

51. Pithon MM, Magno MB, da Silva Coqueiro R, de Paiva SM, Marques LS, Paranhus LR, et al. Oral health-related quality of life of children before, during, and after anterior open bite correction: A single-blinded randomized controlled trial. Am J Orthod Dentofacial Orthop. 2019;156:303-311 .

52. Demirovic K, Habibovic J, Dzemidzic V, Tiro A, Nakas E. Comparison of Oral Health-Related Quality of Life in Treated and Non-Treated Orthodontic Patients. Med Arch. 2019;73:113-117.

53. Arrow P, Brennan D, Spencer AJ. Quality of life and psychosocial outcomes after fixed orthodontic treatment: a 17-year observational cohort study. Community Dent Oral Epidemiol. 2011;39:505-514.

54. Seehra J, Newton JT, Dibiase AT. Interceptive orthodontic treatment in bullied adolescents and its impact on selfesteem and oral-health-related quality of life. Eur J Orthod. 2013;35:615-621.

55. Brosens V, Ghijselings I, Lemiere J, Fieuws S, Clijmans M, Willems G. Changes in oral health-related quality of life reports in children during orthodontic treatment and the possible role of self-esteem: a follow-up study. Eur J Orthod. 2014;36:186-191.

56. Johal A, Alyaqoobi I, Patel R, Cox S. The impact of orthodontic treatment on quality of life and self-esteem in adult patients. Eur J Orthod. 2015;37:233-237.

57. Choi SH, Cha JY, Lee KJ, Yu HS, Hwang CJ. Changes in 
psychological health, subjective food intake ability and oral health-related quality of life during orthodontic treatment. J Oral Rehabil. 2017;44:860-869.

58. Jaeken K, Cadenas de Llano-Pérula M, Lemiere J, Verdonck A, Fieuws S, Willems G. Reported changes in oral healthrelated quality of life in children and adolescents before, during, and after orthodontic treatment: a longitudinal study. Eur J Orthod. 2019;41:125-132.

59. Romero-Maroto M, Santos-Puerta N, González Olmo MJ, Peñacoba-Puente C. The impact of dental appearance and anxiety on self-esteem in adult orthodontic patients. Orthod Craniofac Res. 2015;18:143-155.
60. Avontroodt S, Lemiere J, Cadenas de Llano-Pérula M, Verdonck A, Laenen A, Willems G. The evolution of selfesteem before, during and after orthodontic treatment in adolescents with dental malocclusion, a prospective cohort study. Eur J Orthod. 2020;42:257-262.

61. Peter E, Baiju RM, Varughese JM, Varghese NO. Patientreported outcome measures in orthodontics. Dent Med Res. 2019;7:3-11.

62. Ferrando-Magraner E, García-Sanz V, Bellot-Arcís C, Montiel-Company JM, Almerich-Silla JM, Paredes-Gallardo V. Oral health-related quality of life of adolescents after orthodontic treatment. A systematic review. J Clin Exp Dent. 2019;11(2): e194-e202. 